\title{
Psychophysics in the field: Perception and memory for labor pain
}

\author{
DANIEL ALGOM \\ John B. Pierce Laboratory and Yale University, New Haven, Connecticut \\ and Bar Ilan University, Ramat Gan, Israel \\ and \\ SONIA LUBEL \\ Bar Ilan University, Ramat Gan, Israel
}

\begin{abstract}
Separate groups of women estimated the painfulness of labor contractions either immediately (perceptual judgments) or at time intervals varying from 8 to $48 \mathrm{~h}$ after their completion (memorial judgments). The pain judgments of individual uterine contractions were related functionally to the biometrically measured magnitude of these contractions. Perceived and remembered painful sensations were related to referent intensities by power functions governed, as a rule, by exponents greater than unity. Exponents for the memory functions were consistently greater than those for the perceptual functions. Psychophysics done in the field can help decide theoretical issues in addition to providing useful practical information.
\end{abstract}

Memory for pain in patient populations and cohort controls has received only limited study. The paucity of experimental research on remembered pain is striking, given the latter's preponderance in medical practice, theory, and research alike. Pain is the single most common cause for seeking medical help, yet, in the clinic, often the memory for the referent pain only is available. Virtually all of the studies on memory for pain (e.g., Eich, Reeves, Jaeger, \& Graff-Radford, 1985; Hunter, Philips, \& Rachman, 1979; Kent, 1985; Linton \& Gotestam, 1983; Linton \& Melin, 1982; Pakula \& Milvidaite, 1983; Rofe \& Algom, 1985) have been field investigations conducted on different types of patient populations. Typically, a patient is asked to assess the intensity of the pain that he or she is experiencing; then, after a time interval (ranging from a few days to a few months), the patient is asked to assess again the referent pain from memory. Differences between the two assessments measure the accuracy of remembering pain. However, these studies lack an objective, physical measure of the pain-inducing stimulus, which in turn precludes functionally relating the magnitude of reported pain to measurable properties of the irritating stimulus. More seriously, they all are open to the criticism that the subjects recalled the perceptual judg-

Preparation of this paper was supported by U.S.-Israel Binational Science Foundation Grant 89-00447 to D.A. and by National Instinutes of Health Grant DC 00271 to Lawrence Marks, whose comments on an earlier draft are greatly appreciated. We also thank Martha Teghtsoonian and two anonymous referees for insightful reviews. Portions of these data were presented at the 29th Annual Meeting of the Psychonomic Society in Chicago, November 1988. Correspondence concerning this article should be addressed to D. Algom, Department of Psychology, Bar-Ilan University, Ramat-Gan 52 900, Israel.

-Accepted by previous editor, Charles $W$. Eriksen ments they had given at the first assessment rather than the original pain experience itself.

Laboratory investigations of pain that could, in principle, resolve most of these problems have their own limitations. Laboratory pain and clinical pain differ at least in the source of discomfort and the affective and cognitive reactions of the individual. Clinical pain produced by pathological processes is inevitably linked to the individual's concerns about his or her eventual well-being. The laboratory presents a different context, most notably lacking the anxiety associated with the disease and the threat of disfigurement or death (Weisenberg, 1977). Therefore, the declared capacity of experimental pain to control the spatiotemporal characteristics of the stimulus is hardly advantageous if results cannot be generalized beyond the laboratory (Rollman, 1983b).

The labor of childbirth offers an opportunity for a particularly penetrating way of looking at pain. It satisfies two conditions for valid measurement. First, labor pain arises naturally from an endogenous source laden with a full spectrum of stressful emotions and anxieties. Thus, it clearly is a foremost example of clinical pain, enjoying the genuine character of nociception. Unlike many clinicalpain experiences, however, the irritating stimuli are fully measurable via standard biometric equipment. A second important property of labor pain is, therefore, its amenability to easy quantification at the stimulus end. Labor pain thus combines advantageous features of both laboratory and clinical pain, offering a unique avenue for sensory assessment.

\section{Memory Psychophysics for Pain}

Central to the discipline of psychophysics is the determination of the functional relation(s) between the magnitude of sensations and the objective properties of the rel- 
evant physical stimuli. Memory researchers have long pursued another relation-that between remembered attributes of a stimulus (including its mere appearance in the past) and its objectively verifiable properties. Despite the obvious similarity in goals, the routine of memory psychophysics, in which the rigorous quantitative techniques of perceptual psychophysics are applied to remembered stimuli, has been a fairly recent development (Algom, 1992a, 1992b; Algom \& Cain, 1991a, 1991b; Algom \& Marks, 1989; Algom, Wolf, \& Bergman, 1985; Kerst \& Howard, 1978; Moyer, Bradley, Sorensen, Whiting, \& Mansfield, 1978; Moyer, Sklarew, \& Whiting, 1982; Wolf \& Algom, 1987). Typical procedures of memory psychophysics involve separate examinations of the relations between stimulus magnitude and perceptual judgments (resulting in a perceptual psychophysical function), and between stimulus magnitude and memory-based magnitude judgments (resulting in a memory psychophysical function). Standard psychophysical methods (e.g., magnitude estimation) and analyses (e.g., power function transforms) can be used with both types of judgment, the only difference being that stimuli are physically presented in one case, and symbolically represented (i.e., retrieved from memory) in the other.

Two general findings have emerged from the (rather modest) existing literature on memory psychophysics (see Algom, 1992b, for a recent review). First, remembered stimuli relate to their corresponding physical values via power transforms, much the same way that perceptual scale values do. Second, systematically smaller exponents characterize the memory judgments. Two hypotheses have been suggested to account for this parameter difference.

According to the reperception hypothesis (Kerst \& Howard, 1978; Moyer et al., 1978), perception and memory perform identical transformations on the input data. Following Stevens (e.g., 1975), a simple two-parameter power function describes how perceptual magnitude $R$ increases with physical magnitude $S$. Thus,

$$
R=a S^{b},
$$

where $a$ and $b$ are constants. The exponent is given by $b$, whereas $a$ is an arbitrarily determined measurement modulus. For memory, the same power function applies, but it acts on the perceptually transformed scale values $R$ (rather than to the original physical values). Therefore,

$$
M=a^{\prime} R^{b},
$$

where $M$ is the respective memorial magnitude and $a^{\prime}$ has the same meaning as $a$ in Equation 1. Substituting for $R$ yields

$$
M=A S^{b^{2}},
$$

where $A$ is the new scaling factor.

The reperceptual hypothesis predicts a square relation between a given pair of perceptual and memorial power function exponents.

The alternative formulation, labeled the uncertainty hypothesis, posits that subjects experience greater uncertainty, if not confusion, in the memory-based judgment condition. According to one version (Kerst \& Howard, 1978), this causes them to be more conservative in their magnitude judgments. The resulting response (range) constriction reduces the slope of the memorial psychophysical function. An alternative version (Algom et al., 1985) holds that it is the stimulus dimension (rather than the response continuum) that undergoes changes under the rather fuzzy memory condition. A widening of the stimulus range produces a corresponding decrease in the magnitude of the power function exponent. In our version, the attenuated memory exponent simply constitutes a special case of a general psychophysical principle, namely, the inverse relation between stimulus range and power function exponent ( $R$. Teghtsoonian, 1971, 1973).

It is interesting to examine the implications that the last notion has for memory. Suppose that, due to uncertainty, the representation in memory of an experimental stimulus fluctuates randomly around its perceptually transformed scale value. The net result of the resonance in memory is a larger stimulus range and, possibly, a larger dynamic range-a larger spread of the conceivable values on the referent continuum. R. Teghtsoonian, M. Teghtsoonian, and Karlsson (1976) have shown that the exponent for perceived effort changes when fatigue alters the dynamic range, demonstrating a contingency between range and exponent within a sensory continuum. We submit that memory similarly alters the dynamic range. There are thus two sizes of the dynamic range for any given continuum; one characterizes perception, but another (larger) range applies when the referent stimuli are retrieved from memory. Incidentally, the reperception hypothesis can also be couched in terms of parallel sets of range (and exponent) for perception and memory. That theory allows, however, for different relations between the two modes of cognitive generation.

\section{The Present Study}

Virtually all the data gathered to date within the framework of memory psychophysics have involved compressive sensory continua, a class of perceptual dimensions characterized by smaller-than-unity power function exponents. For such data, both the reperceptual and the uncertainty hypotheses predict an even more compressive memory function-a prediction that has been borne out repeatedly. However, as has been pointed out in the literature (e.g., Algom, 1992b; Algom et al., 1985; Moyer et al., 1978; Wolf \& Algom, 1987), a clear decision between the alternatives must await examination of expansive psychophysical dimensions (i.e., those characterized by power function exponents greater than unity) in which differential predictions exist. For expansive dimensions, the reperceptual hypothesis predicts a steeper memory function (the memory exponent should equal the square of the greater-than-one perceptual exponent), whereas the uncertainty hypothesis predicts an attenuated memory function regardless of the nature of the perceptual relation. The sensation of pain has proven prototypical of all expansive continua (Stevens, 1975). The memory and perception of labor pain examined here may provide the 
needed criterion dimension for the critical theoretical test. Therefore, for both intrinsic interest pertaining to pain and extrinsic considerations bearing upon memory research at large, the present experiment was a test of the perception and memory for painful uterine contractions during labor.

Our aim was to determine the functional relation between magnitude estimates of the pain of individual uterine contractions during chidbirth and the objectively measurable magnitudes of those contractions. Pain estimates were obtained immediately at the completion of a particular contraction (perceptual condition) or at time intervals varying from 8 to $48 \mathrm{~h}$ after the occurrence of the obstetric, contraction-produced painful events (memorybased judgment conditions). For each woman in each condition, we derived the appropriate (perceptual or memorial) psychophysical function for pain.

It is worth briefly pointing out the problems inherent in the use of scales to assess pain. For one, it is risky to take response categories at face value, because it is difficult to specify the size of each category and ascertain that the categories are of equal spacing (Chapman et al., 1985; Heft \& Parker, 1984). Even if we grant that two persons are feeling the same level of pain (a highly unlikely occurrence), they may well use different responses (e.g., verbal descriptors, numbers, marks on a straight line) to label it. Conversely, different levels of pain may receive the same intensity response with various people. All equal-pain ratings do not denote equally painful sensations. Validity is at issue: Ratings cannot be used safely for comparisons across persons, or over different types of pain.

The last point is notable. Judgments of pain are relativistic, showing diversity, individuality, and idiosyncrasy. Yet beneath may lie a common core of uniformity in the psychophysical processing of pain. Although pain reports are labile, pain functions-depicting the relation between pain perception or memory and the inducing stimulimay display more stability. In particular, the parameters of the psychophysical function may well gauge some relatively invariant properties of perceived and remembered pain. Comparison of the parameters of the psychophysical functions (rather than comparisons of pain judgments or reports per se) across conditions and subjects was the tactic followed in the present study.

\section{METHOD}

\section{Subjects}

Sixty-nine women in labor were selected at irregular times around the clock on the basis of availability. Participation in the study required (1) giving natural childbirth to a healthy baby, (2) neither drug intake nor epidural analgesia during labor, (3) no severe maternal systemic diseases, (4) no chronic or acute fetal suffering, (5) no abnormal fetal presentation, and (6) willingness to respond and ability to follow instructions at either immediate assessment or recall.

Of the women approached, 2 declined the offer to take part in the study, 12 failed to grasp the method of judgment or claimed having confusion in remembering labor, and a further 9 failed to meet one or more of the first five criteria.
The subjects were middle to lower class women with a mean age of $26.1 \pm 5.2$ years. Both primiparae and multiparae participated, having a mean of $1.97 \pm 1.29$ childbirths. Although the deliveries were spread over the entire 24 -h period, they tended to occur mainly in the early afternoon at around 14:58 $16.6 \mathrm{~h}$.

All the women attended the same maternity ward of the Serlin Municipal Hospital in Tel Aviv and gave their informed consent to participate in the study.

\section{Apparatus and Procedure}

For the evaluation of the pain-inducing stimuli, we took advantage of the standard obstetric routine of monitoring the pattern of uterine contractions in the course of labor by tocography. Tocographic tracing allows for full specification of the defining parameters of the contractions, namely, their intensity (usually expressed as intrauterine pressure in $\mathrm{mmHg}$ ), duration (usually measured in seconds), and phasic characteristics (e.g., rise and decay time, shape, or frequency). Mathematical elaboration of the respective tocographic sections ("pain curves," cf. Corli, Grossi, Roma, \& Battagliarin, 1986) allows for the derivation of further variables such as the total energy involved in a contraction (i.e., integrating intensity over time).

A Hewlett-Packard cardiotocograph supported by appropriate transducers for tracking fetal heart rate and intrauterine pressure was applied to each woman. A tocographic monitor recorded the changes in pressure on a scrolling chart. Careful calibration of the tocographic equipment was made after its application to the subject and again at the start of the experimental observations. During the phase of cervical dilatation (when the measurements were taken), there are highly visible (and audible) signs of elevated pain at the time of uterine contractions compared with the intervals between consecutive contractions. A "pain curve" corresponding to a given contraction was defined by the respective pair of zero-crossings of the tocographic recording. The results were usually well articulated, approximately inverted V- or U-shaped curves, which provided the data for the physical measurement of the pain-producing stimulus. The judgments of pain given to each of a set of irregularly selected uterine contractions were related functionally to the parameters of their respective pain curves (see Corli et al., 1986, for similar methods and evaluation criteria as well as for an illustration; see also Bonica \& Chadwick, 1989, for a schematic depiction of contraction recording during the full course of labor).

The experimental observations started at the onset of labor, but were mainly made during the latter, active phase of the first stage of labor. Measurements were also taken at the early part of the second stage of labor, but before the beginning of the expulsion phase (see Bonica \& Chadwick, 1989, for a description of the three stages of labor). For the women tested, cervical dilatation varied between 2 and $10 \mathrm{~cm}$ across subjects and assessment times. As a matter of course, only a small minority of the measurements were taken with the cervix fully dilated; the great bulk of our data came from contractions with the cervix dilated between 3 and $7 \mathrm{~cm}$ (gauged by the ward's medical staff who fully cooperated with the experimenter, their routine notwithstanding).

Upon admission to the maternity ward, prospective subjects were approached by a female experimenter to obtain their consent to participate in the study. After giving her consent, a woman was randomly assigned to either a perceptual condition or one of three memory conditions.

In the perceptual condition, the women were instructed to judge the intensity of the pain felt at each of five particular contractions selected for report by the experimenter. In the memorial conditions, the women were instructed to associate colors to each of five similarly selected uterine contractions. Contractions were chosen in an irregular fashion, but we tried to adhere to the following three principles. First, an attempt was made to avoid measuring consecutive contractions; second, we tried to maximize interstimulus interval 
(ISI) for at least some observations; and third, we tried to vary ISI as much as possible. Our aim was to increase the range of pressure magnitudes and the corresponding pain judgments, apart from generating more representative samples for the entire course of labor. Unfortunately, given the dynamics of labor and the occasional need for closer care and intervention, these principles had to be compromised for quite a few of the women. For these subjects, the spacing of stimulus levels was fairly close, impairing our ability to derive meaningful psychophysical functions relating pain to pressure. On the whole, the entire observation time for each subject spanned between 40 and $100 \mathrm{~min}$.

In the memory conditions, during the entire course of a selected contraction, the experimenter showed a large, glossy piece of colored cardboard $(40 \times 15 \mathrm{~cm})$ and stated its color (e.g., read aloud "green") to the subject. The subject was asked to "learn that color label" for the experienced contraction. The procedure sought to firmly establish an associative link between a particular color and the selected contraction, characterized, inter alia, by a particular level of presssure. Order of color presentation was irregular and different for each woman. The women were told that "naming the contractions" comprised part of the experimental project on childbirth in which they had consented to participate. We did not offer information on further stage(s) of the project (if any), and were especially careful to avoid referring to pressure or pain. Thus, the women did not know that they would be questioned later. Virtually all were content to follow the instructions matter-of-factly, as they were presented.

After 8,24 , or $48 \mathrm{~h}$ from the median measured contraction (and, in all cases, after giving birth), the women in the different memory groups were approached again to make their ratings of the contractions. One should regard the delays of 8,24 , and $48 \mathrm{~h}$ as approximately denoting the lower limit of the particular interval. The women were not awakened or otherwise disrupted in order to participate. Hence, deviations from the planned timing were inevitable (amounting in one case to nearly $50 \mathrm{~min}$ ). Fortunately, however, the great majority of the subjects were available at the planned values of delay. Needless to add, meeting those deadlines required meticulous advanced organization along with a great deal of tact on the part of the experimenter.

The method was free-modulus magnitude estimation. The women were instructed to judge "how painful each of the selected contractions feels to you by assigning numbers to stand for the degree of apparent pain. To the first contraction, assign whatever number seems to you most appropriate to represent the degree of pain. Then, assign other numbers in proportion to succeeding contractions. If one contraction seems to you five times as painful as another, assign a number five times as great [here a numerical example was given]. If a contraction feels one tenth as painful as another, assign a number one tenth as great [another illustration with numbers was provided]." The subjects were told that they could use whole numbers, decimals, and fractions as needed. If no pain was felt, the women were to assign the number zero (which none of them did).

In the delayed-judgment groups, reference contractions were represented by their previously learned colors. The women imagined each contraction as the colors were shown and called out one at a time for judgment, then gave estimates of their painfulness. The subjects were cautioned that the order of presentation of the colored cardboards was irregular, and therefore it did not necessarily coincide with the chronological order of the referent contractions. The subjects were instructed to report remembered pain, not other aspects of the contractions. The same magnitude estimation instructions used in the perceptual condition were given in the various memory groups.

\section{RESULTS AND DISCUSSION}

Table 1 shows the results. Listed are parameters of the psychophysical functions for contraction-produced labor pain. Magnitude estimates of pain were related via power functions to peak intensity (pressure) of the respective uterine contractions. Note that the stimulus levels differ as a matter of course across the women as well as their subjective judgments of pain, even for occasionally arising common values of intrauterine pressure. Consequently, only the functional relations (between pain stimulus and sensation) can be meaningfully compared across subjects and conditions. Summary values of these-exponents and goodness of fits of the power transforms-are presented in Table 1 .

Three issues pertaining to data reduction need to be addressed. First, our choice of a power transform was psychophysically guided, predicated on Stevens's approach of

Table 1

Power Function Exponents (Slopes; $b$ ) and Correlations $\left(r^{2} s\right)$ for Perceived and Remembered Labor Pain for 46 Women

\begin{tabular}{|c|c|c|c|c|c|c|c|c|c|c|c|}
\hline \multicolumn{3}{|c|}{ Perception } & \multicolumn{3}{|c|}{ Memory $8 \mathrm{~h}$} & \multicolumn{3}{|c|}{ Memory $24 \mathrm{~h}$} & \multicolumn{3}{|c|}{ Memory $48 \mathrm{~h}$} \\
\hline $\begin{array}{c}\text { Subject } \\
(n=13)\end{array}$ & $b$ & $r^{2}$ & $\begin{array}{c}\text { Subject } \\
(n=11)\end{array}$ & $b$ & $r^{2}$ & $\begin{array}{c}\text { Subject } \\
(n=12)\end{array}$ & $b$ & $r^{2}$ & $\begin{array}{c}\text { Subject } \\
(n=10)\end{array}$ & $b$ & $r^{2}$ \\
\hline 1 & 3.83 & .99 & 14 & 0.85 & .47 & 25 & 4.72 & 1.00 & 37 & 1.19 & .98 \\
\hline 2 & 1.01 & .94 & 15 & 1.05 & .78 & 26 & 2.58 & .17 & 38 & 4.02 & .69 \\
\hline 3 & 1.26 & .86 & 16 & 1.10 & .91 & 27 & 2.76 & .74 & 39 & 1.25 & .98 \\
\hline 4 & 1.00 & 1.00 & 17 & 1.47 & .52 & 28 & 2.04 & .79 & 40 & 2.28 & .17 \\
\hline 5 & 2.71 & .63 & 18 & 1.13 & .99 & 29 & 1.72 & .61 & 41 & 1.99 & .91 \\
\hline 6 & 2.28 & .96 & 19 & 2.62 & .85 & 30 & 3.30 & .31 & 42 & 1.23 & .54 \\
\hline 7 & 1.02 & .89 & 20 & 1.03 & .67 & 31 & 3.74 & .54 & 43 & 1.81 & .91 \\
\hline 8 & 0.77 & 1.00 & 21 & 3.92 & .88 & 32 & 1.32 & .53 & 44 & 3.06 & .97 \\
\hline 9 & 1.67 & .96 & 22 & 1.63 & .99 & 33 & 1.66 & .97 & 45 & 1.17 & .86 \\
\hline 10 & 0.88 & .99 & 23 & 3.08 & 1.00 & 34 & 1.06 & .85 & 46 & 2.20 & .88 \\
\hline 11 & 1.33 & .99 & 24 & 2.43 & .94 & 35 & 0.81 & .61 & & & \\
\hline 12 & 0.86 & .77 & & & & 36 & 1.56 & .81 & & & \\
\hline 13 & 1.77 & .99 & & & & & & & & & \\
\hline$M_{\mathrm{G}}$ & \multicolumn{2}{|c|}{1.387} & \multicolumn{3}{|c|}{1.629} & \multicolumn{3}{|c|}{2.00} & \multicolumn{3}{|c|}{1.749} \\
\hline$S D$ & \multicolumn{2}{|c|}{0.898} & \multicolumn{3}{|c|}{1.016} & \multicolumn{3}{|c|}{1.179} & \multicolumn{3}{|c|}{0.934} \\
\hline
\end{tabular}

Note- $M_{\mathrm{G}}$, geometric mean; $S D$, standard deviation. 
depicting the growth of sensation. Scores of noxious physical dimensions have been fitted by power functions (e.g., Algom, 1992c; Marks, 1974; Stevens, 1975). The uterine contractions measured here arose spontaneously within the subjects, yet they comprise physical stimuli much like electric shocks - the most popular irritants in the literatureapplied experimentally from outside. Hence, similar painintensity contingencies should characterize both. Second, the physical nature of the stimuli notwithstanding, the present circumstances permitted but a single judgment of pain at each of five intensities. This contrasts with the typical practice of obtaining several judgments for a given level of the stimulus.

A third problem, exacerbated by the limitation on the number of observations per stimulus, is the low degree of fit obtained for several of the subjects. Many such cases came from women sustaining contractions marked by equal or very closely spaced levels of pressure. Often, these subjects gave different judgments of pain to the same stimulus levels separated in time, resulting in very low values of fit. We decided to include such subjects in the analyses if their judgments of nonidentical contractions followed the monotonic increase dictated by a power function. Note that it was impossible to pool data over subjects because each subject generated her own levels of the stimulus. Indeed, subjective and spontaneous production of stimuli that nonetheless are fully measurable is the hallmark of the present approach.

\section{Perception}

Several valuable features appear in the data. For 9 of the 13 women, total variance in pain estimation accounted for by measured intrauterine pressure is $94 \%$ or greater. Thus, the present data demonstrate, for the first time, a lawful relation between an endogenous, spontaneously arising source of irritation and overt judgments of pain. Moreover, contraction-produced pain values map onto their physical referents via the same functional relation as experimentally produced pain values do. Power functions are a good description of the data obtained from the individual women for their spontaneously occurring uterine contractions.

The pain scales varied considerably from woman to woman. The slopes (exponents of the power functions) span about a fivefold range, from 0.77 to 3.83 with a (geometric) mean of 1.387 (see Table 1). This variation is hardly surprising. Although we lack both an objective yardstick against which to measure individual differences (Algom \& Marks, 1984) and studies of measured endogenous pain for a comparison, a threefold to sixfold range of exponents is what is usually reported for experimentally induced pain, and, in fact, for some other sensory continua as well (see Rollman, 1992; Rollman \& Harris, 1987, for recent reviews).

In the present study, each woman experienced her own set of painful sensations originating within the organs associated with parturition. The range of experienced intensities differed among the women, but not nearly to the extent required to account for the variation in exponent.
Alternatively, the size of the dynamic range-the entire spectrum of conceivable intensities-could have varied across the women. However, the latter can account for the observed variation in exponent if, in addition, we assume that individuals have the same maximum subjective range (R. Teghtsoonian, M. Teghtsoonian, \& Karlsson, 1981). Both hypotheses of memorial judgment described in the introduction are, in fact, compatible with these assumptions. On the other hand, as Teghtsoonian et al. convincingly claim, the conjecture that maximum subjective range is constant over individuals is a difficult one to test. Moreover, the same authors found no correlation between individual dynamic range and power function exponent.

The present procedure of self-generating painful stimuli can be contrasted with the two conventional experimental methods of stimulus selection. The first method, and the one utilized most often, is to present the same set of stimuli to all observers (e.g., Algom, Raphaeli, \& CohenRaz, 1986, 1987). The second method is an attempt to tailor the stimulus set to each individual's range (e.g., Rollman \& Harris, 1987), thereby acknowledging individual differences explicitly. In the present study, experimental homogenization of stimulus range was, of course, neither possible nor necessary. By their endogenous and clinical nature, the respective sets of contractionproduced painful stimuli were at once wholly individualized and idiosyncratic. And, surely enough, exponents were not constant across women, nor should they be expected to be.

The mean exponent of 1.4 confirms the often reported finding of exponents greater than unity for pain or disagreeable sensations (e.g., Algom et al., 1986, 1987; Rollman, 1974, 1983a, 1983b; Rollman \& Harris, 1987; Stevens, 1975; R. Teghtsoonian, 1971). Of course, the reports in the literature pertain to experimentally induced pain, not to self-generated spontaneous experiences. Nevertheless, the present data also refer to physical stimuli, and the pain grows at a rate fairly similar to that obtained with electric shocks-the prototype of experimentally induced pain (see Algom et al., 1986; Rollman \& Harris, 1987, for recent summaries of that literature). Although there is a vast variability of reported exponents for painful electrical shock, the typical result is an expansive psychophysical function with a representative exponent of around 1.5. Three recent studies by Algom et al. $(1986,1987)$ and Rollman and Harris reported mean exponents of $1.15,1.26$, and 1.74, respectively. Although the respective ranges were $0.70-2.48,0.49-1.96$, and $0.50-9.93$, an overwhelming majority of subjects in all three studies had exponents greater than unity. Clearly, perceived intensity of painful uterine contractions grows at a faster rate than does physical intensity, much the same way that externally produced pain behaves. Likely, these highly accelerated psychophysical functions for pain serve the useful biological role of warning us of impending danger (cf. Marks, 1974).

Given the accessibility of data, the literature on psychophysiological aspects of labor pain is surprisingly scarce. We could find only a single study that also sought 
to explore the relation between subjective labor pain and uterine contractions. Using tocographic data similar to those utilized here, Corli et al. (1986) were able to calculate the correlations between the parameters of the tocographic curves and the corresponding reports of pain for 15 women. They used a bounded, fixed-category visual analogue scale (VAS) for a response measure, and collapsed data across women. The correlations between VAS scores and different curve parameters, although low $(.291 \leq r \leq .373)$, were all significant. Individual analyses (based on an average of about eight contractions per woman) revealed, however, much stronger relations comparable to the $\left(r^{2}\right)$ values reported here. In particular, the highest correlations were found when VAS scores were set against peak intensity; the area under the curve and duration as covariates yielded lower coefficients of correlation.

The present set of data, as well as those by Corli et al. (1986), provides an important caveat with regard to the interpretation of the great bulk of previous research on labor pain. Virtually all extant studies have relied on either a single retrospective rating of the entire experience of labor or on a few one-time ratings from different phases of labor (Bonnel \& Boureau, 1985; Cogan, Henneborn, \& Klopfer, 1980; Melzack, Kinch, Dobkin, Lebrun, \& Taenzer, 1984; Melzack, Taenzer, Feldman, \& Kinch, 1981; Nettelbladt, Fagerstrom, \& Uddenberg, 1976; Niven \& Gijsbers, 1984; Norvell, Gaston-Johansson, \& Fridh, 1987; Pesce, 1987; Rofe \& Algom, 1985). Yet it is highly questionable whether a single estimate or a handful of sporadic judgments can capture the full spectrum of sensations involved in so rich, intricate, and multifarious an experience as labor. One should exercise caution in interpreting such "global" judgments of labor pain and, when possible, not use them for comparisons across pain phenomena. The present results attest to the great variability of irritations coming from even a single origin over a limited span of time. Careful psychophysical decomposition of the labor process can bypass some of the limitations besetting earlier research.

\section{Memory}

The memory data appear in Table 1. The women in these groups also judged the painfulness of uterine contractions. However, those judgments were not perceptual, but were based instead on stimulus representations in memory. We sought to answer the following question: How do psychophysical relations based on remembered pain compare with their perceptual counterpart?

The most striking feature of the memory functions for all three groups is their close correspondence to the respective perceptual results. Although the power approximations are a bit less adequate, in most cases the fits to the memory functions are quite satisfactory. However, the underlying representations for memory differ from the perceptual values that operate when contractions are concurrently assessed for pain. The exponents (geometric means) for memorized pain as a function of referent phys- ical intensity are $1.63,2.00$, and 1.75 for time intervals of 8,24 , and $48 \mathrm{~h}$, respectively. The results suggest a somewhat higher exponent for memory-based judgments than for the regular perceptual judgments. A one-tailed perception versus memory test indeed yields a marginally significant result $[t(44)=-1.48, p<.10]$. Reducing the variance by a logarithmic transform gives a significant perception-memory difference $[t(44)=-1.698$, $p<.05]$.

This means that there is no simple proportionality between either perceived or remembered pain and the physical intensity of the irritating contractions. Instead, the psychophysical relations are expansive, with exponents in the vicinity of 1.4 for perception and 1.8 for memory (the geometric average of memory data over all time delays). It follows that for one contraction to feel twice as painful as another, its intensity would need to be about 1.64 times as great. Yet for one contraction to be remembered as being twice as painful as another, the ratio of physical intensities would need to be no greater than 1.47. Commensurate with the prediction of the reperceptual hypothesis, the memorial psychophysical function is steeper than the already expansive perceptual function. Although the numerical values deviate somewhat from the expected square relation $\left(1.4^{2}=1.96\right)$, the deviation is not great.

A further feature of the data supports the reperception hypothesis: No clear temporal trend is discernible in the magnitude of the exponent. There is a difference between perceptual and memory-based judgments, but once the latter is required, the extent of temporal delay matters little to the growth of remembered pain. This result is consistent with the prediction of the reperception theory (e.g., Algom, 1991, 1992b; Hubbard, 1991; Kemp, 1988), but it is incompatible with the uncertainty hypothesis, which predicts changes in the magnitude of the exponent due to the continuous increase in uncertainty over time. Thus, although the evidence is meager, the reperception hypothesis is the alternative favored by the data. The theoretical implications of this memory-percept relation for memory research are readily apparent.

Remembered pain is lawfully related to the physical intensity of the referent noxious stimulus. Moreover, the psychophysical function for memory is of the same class mathematically as the one characterizing perceived pain. Notably, both psychophysical relations apply to clinical pain arising spontaneously within the subject. Remembered pain grows at a faster rate than does perceived pain as a function of a given set of noxious stimuli.

Recall part of our motivation for selecting pain: It might provide the leverage to differentiate alternative theories of memorial judgment. For pain, an expansive psychophysical continuum, the reperception and uncertainty hypotheses predict opposite directions of change over time. Although the data diagnosis proved less definite than we had hoped, the results were consistent with the reperception theory. The ecological validity of this study-elucidating characteristics of self-generated, endogenous nociception in its natural habitat-confers support on this conclusion. The 
study also rules out an alternative, artifactual account that has beset previous investigations of memory for pain. Our design ensured that the subjects judged remembered pain rather than a previously given judgment of pain, simply because all of them provided but a single assessment.

Why does pain from memory develop more rapidly than pain felt instantaneously? Likely, the steeper memory function comprises a learned defense reaction, or an advanced warning device. It resembles the adaptive role served by pain that occurs before serious injury or damage (cf. Melzack \& Wall, 1988) and, hence, has real survival value. Remembered pain can trigger withdrawal and other actions aimed at avoiding threat and damage. The importance of an expansive psychophysical function for concurrent pain has been widely documented. The even more expansive function for memory serves a biologically useful purpose that seems equally adaptive: To prevent further injury to an organ that has already sustained damage and pain.

The present study was concerned with the form of the psychophysical function for remembered pain. The function proved expansive, and steeper, in fact, than the parallel function for perceived pain. Expansive growth should not be confused with overestimation. The form of the psychophysical function and the magnitude of judgments are independent issues. Only the former was tested here. Previous studies have examined the latter, but at the cost of asking the subject to assess the referent pain twice (during labor and postpartum). That tactic jeopardized validity, because there is no way to disentangle memory for the original pain and memory for its first assessment.

A recent study by Norvell et al. (1987) may serve to illustrate some of the problems plaguing earlier research. Assessment of a given phase of labor was obtained prospectively during labor, and again, retrospectively, 2 days postpartum. Fortunately, validity was less of a problem in that study because pain was gauged by using a visual analog scale. More pejoratively perhaps, the use of a single judgment to represent the pain felt during the full course of a given phase of labor-littered, as it usually is, by a variety of stressful events and distractions-is questionable. It is not clear what such "global" judgments actually measure, or whether the prospective and retrospective assessments measure exactly the same referent. Finally, Norvell et al. found poor memory for pain for many of their subjects. So did we for a minority of ours. Note, however, that our subjects judged well-delineated, isolated contractions, the paramenters of which are measurable-not extended periods of distress lacking physical description. The latter measures naturally are vulnerable to the elusive influences of emotions and anxiety; one-time assessments of specific contractions are affected to a lesser extent. Again, decomposing the process of labor psychophysically enhances memory, reduces variability, and bypasses many of the methodological intricacies posed by the environmental constraints.

Table 1 presents data for peak intensity as the argument of the (power) functions. However, as indicated, pain es- timates can be related to other parameters of the corresponding tocographic curves. Accordingly, the data were subjected to several analyses using, in turn, different parameters of the curves as the independent variable. Somewhat surprisingly to us, the duration of a contraction bore no significant relation to its painfulness. The median correlation was .40 , accounting for only $16 \%$ of the variance in pain estimates. As a result, perhaps, total energy is moderately related to overt judgments of pain (median correlation of .77). Corli et al. (1986) also found that intensity displayed the strongest association with painfulness. Moreover, they reported no significant correlations at the individual level between pain and duration of the contraction. Intensity and rising time are particularly important in generating pain, but duration of the signal apparently is not.

Labor, of course, is a progressive process that develops dynamically. To incorporate some of the gradual changes, we performed analyses of covariance partialing out any effect of the frequency of contractions. To be sure, contractions become more frequent over the course of labor. Yet the results of the intensity of pain hardly change, even yielding somewhat better values of fit. The mean exponents become 1.36, 1.56, 1.62, and 1.62 for judgments made instantly, or 8,24 , or $48 \mathrm{~h}$ after labor, respectively. To follow the temporal evolution of pain intensity over the entire course of labor, we calculated the correlations, individually for each parturient, between pain and time elapsed from the onset of labor (e.g., Bonnel \& Boureau, 1985). Although the positive correlations confirmed the generally upward trend of pain during labor (median product-moment correlations were $.56, .18, .41$, and .68 for judgments made after 0-, 8-, 24-, and 48-h time intervals), the correlations were not nearly as high as those between pain and contraction intensity. Thus, although contraction intensity and time in labor are closely associated, the correlation is far from perfect.

Finally, correlations were obtained between the power function exponents and a large set of typically documented background variables such as socioeconomic status, ethnic origin, age, number of previous childbirths, menstrual difficulties, time of delivery, and height. Contrary to occasional reports of reciprocity in the literature (e.g., Melzack, 1984; but see Rofe \& Algom, 1985), none of these variables evidenced a significant correlation with the rate of perceived or remembered pain. Note, however, that previous reports pertain to correlations with absolute judgments of pain, whereas the present data are based on correlations with a rate-of-growth parameter. The latter is preferable because, as indicated in the introduction, it is risky to compare judgments across individuals and classes of pain (see Rollman, 1992, for a recent discussion of the problems associated with adequate measurement of pain).

\section{Conclusions}

These results are intriguing and, despite the modulating effect of the great variability, encouraging. Not only do remembered experiences relate in an orderly fashion 
to their objectively discernible antecedents, but they map onto their physical referents in the same way that perceptual scale values do. Striking, too, is the fact that the demonstrated uniformity applies to painful sensations of endogenous origin. For the first time, the functional dependency on intensity of remembered clinical pain is demonstrated and specified. Comparison with perceived pain shows that, for at least an interval of 2 days, memory for labor pain grows at a faster rate than does perceived pain as a function of contraction intensity.

\section{REFERENCES}

ALGOM, D. (1991). Memory psychophysics for area: Effect of length of delay. Perceptual \& Motor Skills, 72, 296.

ALGOM, D. (1992a). Introduction to psychophysical approaches to cognition. In D. Algom (Ed.), Psychophysical approaches to cognition (pp. 1-12). Amsterdam: Elsevier.

Algom, D. (1992b). Memory psychophysics: An examination of its perceptual and cognitive prospects. In D. Algom (Ed.), Psychophysical approaches to cognition (pp. 441-513). Amsterdam: Elsevier.

ALGOM, D. (1992c). Psychophysical analysis of pain: A functional approach. In H.-G. Geissler, S. W. Link, \& J. T. Townsend (Eds.), Cognition, information processing, and psychophysics: Basic issues (pp. 267-291). Hillsdale, NJ: Erlbaum.

Algom, D., \& CAIN, W. S. (1991a). Chemosensory representation in perception and memory. In S. J. Bolanowski, Jr., \& G. A. Gescheider (Eds.), Ratio scaling of psychological magnitude (pp. 183-198). Hillsdale, NJ: Erbaum.

Algom, D., \& CAIN, W. S. (1991b). Remembered odors and mental mixtures: Tapping reservoirs of olfactory knowledge. Joumal of Experimental Psychology: Human Perception \& Performance, 17, 1104-1119.

Algom, D., \& MARKs, L.E. (1984). Individual differences in loudness processing and loudness scales. Journal of Experimental Psychology: General, 113, 571-593.

Algom, D., \& MARKs, L.E. (1989). Memory psychophysics for taste. Bulletin of the Psychonomic Society, 27, 257-259.

Algom, D., Raphaeli, N., \& Cohen-Raz, L. (1986). Integration of noxious stimulation across separate somatosensory communication systems: A functional theory of pain. Journal of Experimental Psychology: Human Perception \& Performance, 12, 92-102.

Algom, D., Raphaeli, N., \& Cohen-Raz, L. (1987). Pain combines additively across different sensory systems: A further support for the functional theory of pain. Perceptual \& Motor Skills, 65, 619-625.

Algom, D., Wolf, Y., \& Bergman, B. (1985). Integration of stimulus dimensions in perception and memory: Composition rules and psychophysical relations. Journal of Experimental Psychology: General, 114, 451-471.

BonicA, J. J., \& Chadwick, H. S. (1989). Labour pain. In P. D. Wall \& R. Melzack (Eds.), Textbook of pain (pp. 482-499). Edinburgh: Churchill Livingstone.

Bonnel, A. M., \& Boureau, F. (1985). Labor pain assessment: Validity of a behavioral index. Pain, 22, 81-90.

Chapman, C. R., Casey, K. L., Dubner, R., Foley, K. M., Gracely, R. H., \& Reading, A. E. (1985). Pain measurement: An overview. Pain, 22, 1-31.

Cogan, R., Henneborn, W., \& Klopfer, F. (1980). Predictors of pain during childbirth. Joumal of Psychosomatic Research, 20, 523-533.

Corli, O., Grossi, E., Roma, G., \& Battagliarin, G. (1986). Correlation between subjective labour pain and uterine contractions: $A$ clinical study. Pain, 26, 53-60.

Eich, E., Reeves, J. L., JAEGER, B., \& GRAFF-RADFORD, S. B. (1985). Memory for pain: Relation between past and present pain intensity. Pain, 23, 375-379.

Heft, M. W., \& PARKer, S. R. (1984). An experimental basis for revising the graphic rating scale for pain. Pain, 19, 153-161.
Hubbard, T. L. (1991). Temporal aspects of memory psychophysics. Unpublished manuscript.

Hunter, M., Philips, C., \& Rachman, S. (1979). Memory for pain. Pain, 6, 35-46.

KemP, S. (1988). Memorial psychophysics for visual area: The effect of retention interval. Memory \& Cognition, 16, 431-436.

Kent, G. (1985). Memory for dental pain. Pain, 21, 187-194.

Kerst, S. M., \& Howard, J. H., JR. (1978). Memory psychophysics for visual area and length. Memory \& Cognition, 6, 327-335.

Linton, S. J., \& GotestaM, K. G. (1983). A clinical comparison of two pain scales: Correlation, remembering chronic pain, and a measure of compliance. Pain, 17, 57-65.

Linton, S. J., \& Melin, L. (1982). The accuracy of remembering chronic pain. Pain, 13, 281-285.

MaRKs, L. E. (1974). Sensory processes: The new psychophysics. New York: Academic Press.

Melzack, R. (1984). The myth of painless childbirth. Pain, 19, 321-327.

Melzack, R., Kinch, R., Dobkin, P., Lebrun, M., \& Taenzer, P. (1984). Severity of labour pain: Influence of physical as well as psychological variables. Canadian Medical Association Journal, 130, 579-584.

Melzack, R., TaEnzer, P., Feldman, P., \& Kinch, R. (1981). Labour is still painful after prepared childbirth. Canadian Medical Association Journal, 125, 357-363.

Melzack, R., \& Wall, P. D. (1988). The challenge of pain. London: Penguin.

Moyer, R. S., Bradley, D. R., Sorensen, M. H., Whiting, J. D., \& MANSFIELD, D. P. (1978). Psychophysical functions for perceived and remembered size. Science, 200, 330-332.

Moyer, R. S., Sklarew, P., \& Whiting, J. (1982). Memory psychophysics. In H.-G. Geissler \& P. Petzold (Eds.), Psychophysical judgment and the process of perception (pp. 35-46). Berlin: VEB Deutscher Verlag der Wissenchaften.

NetTelbladt, P., Fagerstrom, C. F., \& UdDenberg, N. (1976). The significance of reported childbirth pain. Journal of Psychosomatic Research, 20, 215-221.

Niven, C., \& GiJsbers, K. (1984). A study of labour pain using the McGill Questionnaire. Social Science \& Medicine, 19, 1347-1351.

Norvell, K. T., Gaston-Johansson, F., \& FrIDH, G. (1987). Remembrance of labor pain: How valid are retrospective pain measurements? Pain, 31, 77-86.

Paxula, A., \& Milvidaite, I. (1983). Memory for acute coronary pain: Decay with time versus reliability measures. In J. J. Bonica, U. Lindblom, \& A. Iggo (Eds.), Advances in pain research and therapy (Vol. 5, pp. 877-885). New York: Raven.

PEsce, B. (1987). Measurement of reported pain of childbirth: A comparison between Australian and Italian subjects. Pain, 31, 87-92.

RoFE, Y., \& Algom, D. (1985). Accuracy of remembering postdelivery pain. Perceptual \& Motor Skills, 60, 99-105.

Rollman, G. B. (1974). Electrocutaneous stimulation. In F. A. Geldard (Ed.), Cutaneous communication systems and devices (pp. 3851). Austin, TX: The Psychonomic Society.

Rollman, G. B. (1983a). Measurement of experimental pain in chronic pain patients: Methodological and individual factors. In R. Melzack (Ed.), Pain and measurement and assessment (pp. 251-258). New York: Raven.

Rollman, G. B. (1983b). Multiple subjective representations of experimental pain. In J. J. Bonica, U. Lindblom, \& A. Iggo (Eds.), Advances in pain research and therapy (Vol. 5, pp. 865-869). New York: Raven.

RollmaN, G. B. (1992). Cognitive effects in pain and pain judgments. In D. Algom (Ed.), Psychophysical approaches to cognition (pp. 515574). Amsterdam: Elsevier.

Rollman, G. B., \& Harris, G. (1987). The detectability, discriminability, and perceived magnitude of painful electrical shock. Perception \& Psychophysics, 42, 257-268.

Stevens, S. S. (1975). Psychophysics: Introduction to its perceptual, neural, and social prospects. New York: Wiley.

Teghtsoonian, R. (1971). On the exponents in Stevens' law and the constant in Ekman's law. Psychological Review, 78, 71-80. 
TEGHTSOONIAN, R. (1973). Range effects in psychophysical scaling and a revision of Stevens' law. American Joumal of Psychology, 86, 3-37.

Teghtsoonian, R., Teghtsoonian, M., \& Karlsson, J.-G. (1976). The effects of fatigue on the perception of muscular effort. In G. Borg (Ed.), Physical work and effort (pp. 157-180). Oxford: Pergamon. Teghtsoonian, R., Teghtsoonian, M., \& Karlsson, J.-G. (1981). The limits of perceived magnitude: Comparison among individuals and among perceptual continua. Acta Psychologica, 49, 83-94.

Weisenberg, M. (1977). Pain and pain control. Psychological Bulletin, 84, 1008-1044.
Wolf, Y., \& Algom, D. (1987). Perceptual and memorial constructs in children's judgments of quantity: A law of across-representation invariance. Joumal of Experimental Psychology: General, 116, 381-397.

(Manuscript received August 14, 1992; revision accepted for publication July 6,1993 .) 